\title{
World Kidney Day 2016: Awareness for Saving Kidneys
}

\author{
Hamid Nasri, ${ }^{1}$ Parto Nasri, ${ }^{2}$ Azar Baradaran, ${ }^{2}$ Zahra Abedi-Gheshlaghi, ${ }^{3}$ and Mahmoud \\ Rafieian-Kopaei ${ }^{4, *}$ \\ ${ }^{1}$ Department of Internal Medicine, Isfahan University of Medical Sciences, Isfahan, IR Iran \\ 2 Department of Pathology, Isfahan University of Medical Sciences, Isfahan, IR Iran \\ ${ }^{3}$ Nickan Research Institute, Isfahan, IR Iran \\ ${ }_{4}^{4}$ Medical Plants Research Center, Shahrekord University of Medical Sciences, Shahrekord, IR Iran \\ ${ }^{*}$ Corresponding Author: Mahmoud Rafieian-Kopaei, Medical Plants Research Center, Shahrekord University of Medical Sciences, Shahrekord, IR Iran. Tel: +98-3813346692, \\ Fax:+98-3813330709, E-mail: rafieian@yahoo.com
}

Received 2015 August 10; Accepted 2015 August 24.

\begin{abstract}
Context:The general message of the world kidney day is a concerted knowledge against the illnesses that lead to end-stage kidney failure, through better education, improved economic opportunity, increasing community outreach and access to protective medicine for individuals at the highest risk. These might end the unacceptable relationship between chronic renal failure and disadvantages in these societies.

Evidence Acquisition: Annually, world kidney day reminds us that renal disease is a common harmful complication and in many cases treatable. The task of the world kidney day is to develop consciousness so that everybody cares for their kidneys and, if suitable, check and assess if they are at risk of renal disease. Prevention of renal disease, prompt recognition, and following renal protection protocols are serious goals for the world kidney day.

Results: As an annual global alertness and education event, the 2013 World Kidney Day focused on increased awareness of acute renal failure among hospital staff and physicians and the necessity for a public awareness campaign to clarify this hazardous situation and make 'kidney attack' recognizable for the community, similar to that conducted by stroke and heart attack campaigns. Currently, acute renal failure is inefficiently directed in clinical education and training, and mainly ignored by people.

Conclusions: Prevention of renal disease, prompt recognition, and following renal protection are serious goals of the world kidney day.
\end{abstract}

Keywords: Acute Kidney Injury, Diabetic Nephropathies, Diabetes Mellitus, Chronic Kidney Disease, World Kidney Day, Herbal Medicines

\section{Context}

The 11th anniversary of the world kidney day will take place on March 10th 2016, with the participation of the international society of nephrology (ISN) and the international federation of kidney foundations (IFKF). Subsequent to its beginning in 2006, world kidney day has become the most successful attempt ever mounted to raise knowledge of decision-makers and the general public regarding the magnitude of renal disease (1).

\section{Evidence Acquisition}

\subsection{World Kidney Day and Chronic Kidney Disease}

Chronic renal failure is a progressive loss of renal function over a period of months or years (2-7). Each of the kidneys has around a million tiny filters, called nephrons. If nephrons are injured, they stop functioning. The healthy kidney can take on the extra work for a while. However, if the injury continues, more and more nephrons will be blacked. After a certain point, the nephrons that are left cannot filter the blood adequate enough to stay healthy. When renal function falls below a certain point it is called renal failure. Renal failure influences the whole body and can make the involved person feel very sick. Untreated renal insufficiency can be life-threatening (5-7). It should be reminded that early chronic renal failure has no signs or symptoms (8-10). Also, chronic renal disease usually does not go away. Likewise, renal disease can be treated (9-11). Additionally, blood and urine tests are periodically applicable to check for renal diseases. Unfortunately, renal failure can progress to end-stage kidney failure. Hence, the first concern of undetected chronic renal failure is the risk of developing progressive loss of renal function that can lead to permanent renal failure, which requires regular dialysis therapy or a renal transplant. Importantly, the second significance of chronic renal failure is that, it increases the risk of premature death from associated heart disease such as heart attacks or strokes. People who appear to be 
healthy yet are then found to have chronic renal failure are at an increased risk of premature death from heart disease regardless of whether they ever develop renal failure (11). Renal disease can influence people of all ages and races $(12,13)$. Around $10 \%$ of the world's population suffers from chronic renal failure, and this proportion can increase to as high as $50 \%$ for those above the age of 75 years (14). It should be noted that hypertension and diabetes mellitus are the most common causes of chronic renal failure (15). Hypertension causes only over a quarter of all cases of renal failure. Diabetes mellitus has been recognized as the cause of around one-third of all cases and is the commonest cause of end-stage kidney failure in most developed countries (1619). Other less common situations include various glomerulonephritis, or pyelonephritis (20). Sometimes chronic renal failure is inherited, such as in autosomal dominant polycystic disease (ADPKD) or the result of long-lasting obstruction of the urinary system like enlarged prostate or renal stones (21). Moreover, various medications can cause chronic renal failure, particularly analgesics if used over a long time $(22,23)$. The proportion of older people in the general population is steadily growing globally, with the most rapid development in low or middle-income countries. However, aging of the population also has significant implications for the society. Since the prevalence of chronic renal failure is higher in older populations, the health impact of population aging is a concern (24). In 2013, world kidney day concentrated on the impact and consequences of acute renal failure (25-28), while in 2014, the World Kidney Day, focused on chronic renal failure and aging (29).

\subsection{World Kidney Day and Acute Kidney Injury}

As an annual global alertness and education event, the 2013 world kidney day focused on increased awareness of acute renal failure among hospital staff and physicians and the necessity for a public awareness campaign to clarify this hazardous situation and make 'kidney attack' recognizable for the community, similar to that conducted by stroke and heart attack campaigns. Currently, acute renal failure is inefficiently directed in clinical education and training, and mainly ignored by people (30). This has resulted wasted occasions to diminish risk, increased lengths of hospital stay, delayed diagnosis and poor management, which together attribute to strengthen health care costs (31). In 2013, by focusing on 'kidney attack', the world kidney day pursued to promote awareness of acute renal failure and provoke education, policy development and discussion, for the improvement of prevention and therapy of this major renal disease alongside the world (32).

\subsection{The World Kidney Day 2016}

The 2016 world kidney day will focus on chronic renal failure in disadvantaged populations. In fact, various recent investigations have shown that the augmented burden of chronic renal failure in disadvantaged populations is due to both global circumstances and popula- tion-specific matters. Low socioeconomic condition and poor access to care attribute to health-care differences and worsen the negative impacts of genetic or biologic predisposition. Provision of appropriate kidney care to these individuals necessitates a two-pronged modality, firstly to expand the reach of dialysis and secondly application and consideration of cost-effective prevention approaches. Additionally, renal transplantation should be encouraged by expanding deceased donor transplant plans and use of inexpensive generic immunosuppressive medications (33). While in chronic renal failure the impairment of the kidneys is usually permanent, modalities should be put in place to help slow-down chronic renal failure and save the injury from getting worse. To reach this aim, we should encourage controlling of blood sugar in patients with diabetes (34-36). Additionally, we should keep the blood pressure at an appropriate level (36-38). Moreover, to encourage eating a heart healthy diet such as a diet low in salt and fat, we should encourage exercising most days of the week. Furthermore, the patients should be reminded to keep a healthy weight and withdraw from smoking or use tobacco. Finally, the patients should notify their physicians regarding all their medications (39-43).

\subsection{Hazardous and Beneficial Effects of Herbal Drugs on the Kidney}

In recent years much attention has been directed toward potential beneficial effects of herbal drugs on morphology and function of kidneys (44-49). However, it should be reminded that herbs might have direct toxicity for renal tissue. This toxicity is thought to result from progressive fibrosis of the kidney interstitium and damage to the renal tubular cells (50). Some herbs can have anti-inflammatory effects, mediated by alteration of prostaglandin synthesis (51), and even influence angiotensin-converting enzyme inhibition $(52,53)$, hence, patients who innocently take large quantities of herbs, with these effects, may experience a decline in kidney function (53). It should be noted that various patients are taking a variety of drugs for blood pressure, and often for blood glucose control $(36,54-57)$. Herbs also might potentiate the consequences of the patient's drugs $(36,56)$. Although they may be beneficial in allowing the patients to taper their pharmaceutical agents, however, they should be used with caution, and with the notification of the patient's primary physician (58). Despite these concerns, it should be noted that plant products could produce tremendous benefits for patients with kidney failure, if administered judiciously $(59,60)$.

\section{Results}

Several herbs have been detected to be kidney protective in animal models of drug toxicity (61-65). After administration of a nephrotoxic agent, it is supposed that tubule cells die and the medulla becomes ischemic, ensuing in the gen- 
eration of free radicals by remaining viable cells (66). Several herbal drugs with potent antioxidant properties have been shown to be capable of preventing injury by scavenging oxygen radicals in known circumstances (67-74), where kidney toxicity may result, such as administration of nephrotoxic drugs or exposure to radiocontrast agents (70-74). These medicinal plants primarily affecting as a specific kidney antioxidants and also act as anti-proliferative in vivo. There is also many evidences of being beneficial in various renal disease or glomerulopathies in vivo (70). In fact, in the recent years, an increasing proportion of people have been taking complementary and alternative medicines (75-77). Herbal drug therapy appears most promising, thus necessary toxicity investigations should be conducted on these therapies $(78,79)$. Recent investigations have detected that several herbal drugs may exert renal toxicity by their inherent properties. If detected to have some quantity of toxicity, the risks might be weighed against the profits and decisions can be made regarding their continued availability, in a fashion similar to that presently performed for nephrotoxic pharmaceutical substances (76). Therefore, a diet rich in vegetables and fruits significantly diminishes the risk of cardiac diseases, type II diabetes mellitus, various types of carcinoma, Alzheimer's disease, obesity and kidney toxicity. This consequence can be further augmented by consuming nuts, wholegrain foods, and certain oils (omega-3 oils). Diets low in fat and high in fiber may diminish heavy metal risks alongside their other benefits (76-79). High antioxidant herbal foods and sulfur compounds could be protective against heavy metal toxicity in addition to other benefits like decreasing risk of renal failure. Indeed, for the treatment of chronic renal disease, diet is an important part of the treatment. Notably, the inherent properties of the herbs are not the only source of herb-associated kidney disorders, as herb-drug interactions, mistakes in dosage and identification, and contaminants within the mixture are all subjects of concern. Hence, strict controls on the presence of contaminants within herbal drugs, labeling of dosages and contraindications, and manufacturing techniques should be kept to guarantee the safety of those consuming herbal remedies (76).

\section{Conclusions}

The general message of the world kidney day is a concerted knowledge against an illnesses that leads to endstage kidney failure, through better education, improved economic opportunity, increasing community outreach and access to protective medicine for individuals at highest risk, which could end the unacceptable relationship between chronic renal failure and disadvantage in these societies. Annually, the world kidney day reminds us that renal disease is common and harmful yet in many cases treatable. The task of the world kidney day is to develop consciousness so that everybody cares for his or her kidneys and checks to assess if they are at risk for renal disease. Prevention of renal disease, prompt recognition, and following renal protection are serious goals of the world kidney day.

\section{Authors' Contributions}

Main draft by Hamid Nasri, Parto Nasri and Azar Baradaran. Editing by Zahra Abedi-Gheshlaghi and Mahmoud Rafieian-Kopaei. All authors read and sign the final manuscript.

\section{References}

1. Tamadon MR, Zahmatkesh M. World kidney day 2015. J Parathyr Dis. 2015;3(2):34-6.

2. Baradaran A, Nasri H. Correlation of serum magnesium with serum parathormone levels in patients on regular hemodialysis. Saudi J Kidney Dis Transpl. 2006;17(3):344-50.

3. Behradmanesh S, Nasri H. Association of serum calcium with level of blood pressure in type 2 diabetic patients. J Nephropathol. 2013;2(4):254-7.

4. Nasri H, Yazdani M. The relationship between serum LDL-cholesterol, HDL-cholesterol and systolic blood pressure in patients with type 2 diabetes. Kardiol Pol. 2006;64(12):1364-8.

5. Baradaran A. Lipoprotein(a), type 2 diabetes and nephropathy; the mystery continues.J Nephropathol. 2012;1(3):126-9.

6. Mardani S, Nasri H. Catastrophic antiphospholipid syndrome presented with sudden renal failure and history of long-lasting psychosis and hypertension in a 42 years old women. J Nephropathol. 2013;2(2):110-3.

7. Nasri H, Baradaran A. Correlation of serum magnesium with dyslipidemia in maintenance hemodialysis patients. Acta Medica (Hradec Kralove). 2004;47(4):263-5.

8. Dhaun N, Webb DJ. The road from AKI to CKD: the role of endothelin. Kidney Int. 2013;84(4):637-8.

9. Nasri H, Baradaran HR. Lipids in association with serum magnesium in diabetes mellitus patients. Bratisl Lek Listy. 2008;109(7):302-6.

10. Mubarak M, Nasri H. What nephrolopathologists need to know about antiphospholipid syndrome-associated nephropathy: Is it time for formulating a classification for renal morphologic lesions? J Nephropathol. 2014;3(1):4-8.

11. Kellum JA, Lameire N. Diagnosis, evaluation, and management of acute kidney injury: a KDIGO summary (Part 1). Crit Care. 2013;17(1):204.

12. Nasri H. Renoprotective effects of garlic. J Renal Inj Prev. 2013;2(1):27-8.

13. O'Hare AM, Choi AI, Bertenthal D, Bacchetti P, Garg AX, Kaufman JS, et al. Age affects outcomes in chronic kidney disease.J Am Soc Nephrol. 2007;18(10):2758-65.

14. Nasri H, Ahmadi A, Baradaran A, Momeni A, Nasri P, Mardani S, et al. Clinicopathological correlations in lupus nephritis; a single center experience. J Nephropathol. 2014;3(3):115-20.

15. Nasri H, Kheiri S. Effects of diabetes mellitus, age, and duration of dialysis on parathormone in chronic hemodialysis patients. Saudi J Kidney Dis Transpl. 2008;19(4):608-13.

16. Behradmanesh S, Horestani MK, Baradaran A, Nasri H. Association of serum uric acid with proteinuria in type 2 diabetic patients. J Res Med Sci. 2013;18(1):44-6.

17. Atkins RC. The epidemiology of chronic kidney disease. Kidney Int. 2005;67:S14-S18.

18. Baradaran A, Madihi Y, Merrikhi A, Rafieian-Kopaei M, Nasri H. Serum lipoprotein (a) in diabetic patients with various renal function not yet on dialysis. PakJ Med Sci. 2013;29(1):354-7.

19. Rafieian-Kopaei M, Behradmanesh S, Kheiri S, Nasri H. Association of serum uric acid with level of blood pressure in type 2 diabetic patients. Iran J Kidney Dis. 2014;8(2):152-4

20. Wijewickrama ES, Weerasinghe D, Sumathipala PS, Horadagoda C, Lanarolle RD, Sheriff RM. Epidemiology of chronic kidney disease in a Sri Lankan population: experience of a tertiary care center. Saudi J Kidney Dis Transpl. 2011;22(6):1289-93.

21. Witzgall R, Kranzlin B, Gretz N, Obermuller N. Impaired endo- 
cytosis may represent an obstacle to gene therapy in polycystic kidney disease. Kidney Int. 2002;61(1 Suppl):S132-7.

22. Nasri H, Rafieian-Kopaei M. Kidney tubular cell protection; recent findings. Iran J Pediatr. 2014;24(6):781-3.

23. Nasri H, Tavakoli M, Ahmadi A, Baradaran A, Nematbakhsh M, Rafieian-Kopaei M. Ameliorative effect of melatonin against contrast media induced renal tubular cell injury. PakJ Med Sci. 2014;30(2):261-5

24. Tonelli M, Riella M. Chronic kidney disease and the aging population. Indian J Nephrol. 2014;24(2):71-4.

25. Ardalan MR, Nasri H. Acute kidney injury; the focus of world kidney day in 2013. J Nephropharmacol. 2013;2(2):15-6.

26. Nasri H. World kidney day 2013: acute kidney injury; a public health aware. Iran J Public Health. 2013;42(3):338-40.

27. Lala HA, Singh JK, Lala MA. Interrelation between blood pressure and diabetes. J Renal Endocrinol. 2015;1:e05.

28. Nouri P, Nasri H. Irisin and kidney disease; new concepts. J Renal Endocrinol. 2015;1:e03.

29. Nasri H. The awareness of chronic kidney disease and aging; the focus of world kidney day in 2014. J Nephropharmacol.2014;3(1):1-2.

30. Lewington AJ, Cerda J, Mehta RL. Raising awareness of acute kidney injury: a global perspective of a silent killer. Kidney Int. 2013;84(3):457-67.

31. Liu SW, Singer SJ, Sun BC, Camargo CJ. A conceptual model for assessing quality of care for patients boarding in the emergency department: structure-process-outcome. Acad Emerg Med. 2011;18(4):430-5.

32. Tamadon MR., Ardalan MR., Nasri H. World Kidney Day 2013; acute renal injury; a global health warning. J Parathyr Dis. 2013;1(2)

33. Rahimi Z, Moradi M, Nasri H. A systematic review of the role of renin angiotensin aldosterone system genes in diabetes mellitus, diabetic retinopathy and diabetic neuropathy.J Res Med Sci. 2014;19(11):1090-8.

34. Nasri H. Association of serum lipoprotein (a) with hypertension in diabetic patients. Saudi J Kidney Dis Transpl. 2008;19(3):420-7.

35. Nasri H, Baradaran A, Ardalan MR, Mardani S, Momeni A Rafieian-Kopaei M. Bright renoprotective properties of metformin: beyond blood glucose regulatory effects. Iran J Kidney Dis 2013;7(6):423-8.

36. Musabayane CT. The effects of medicinal plants on renal function and blood pressure in diabetes mellitus. Cardiovasc J Afr. 2012;23(8):462-8.

37. Nasri H. Hypertension and renal failure with right arm pulse weakness in a 65 years old man. J Nephropathol. 2012;1(3):130-3.

38. Nasri H, Behradmanesh S, Ahmadi A, Rafieian-Kopaei M. Impact of oral vitamin $\mathrm{D}$ (cholecalciferol) replacement therapy on blood pressure in type 2 diabetes patients; a randomized double-blind, placebo controlled clinical trial. J Nephropathol. 2014;3(1):29-33.

39. Khoodadadi S. Role of Herbal Medicine in Boosting Immune System. Immunopathol Persa. 2015;1:e01.

40. Mardani S, Nasri H, Hajian S, Ahmadi A, Kazemi R, Rafieian-Kopaei M. Impact of Momordica charantia extract on kidney function and structure in mice. J Nephropathol. 2014;3(1):35-40.

41. Rafieian-Kopaei M, Baradaran A, Merrikhi A, Nematbakhsh M, Madihi Y, Nasri H. Efficacy of Co-administration of Garlic Extract and Metformin for Prevention of Gentamicin-Renal Toxicity in Wistar Rats: A Biochemical Study. Int J Prev Med. 2013;4(3):258-64.

42. Mardani S, Nasri H, Rafieian-Kopaei M, Hajian S. Herbal medicine and diabetic kidney disease. J Nephropharmacol. 2013;2(1):1-2.

43. Nasri H. C-Phycocyanin attenuates cisplatin-induced nephrotoxicity in mice. Ren Fail. 2013;35(7):1054-5.

44. Madihi Y, Merrikhi A, Baradaran A, Rafieian-kopaei M, Shahinfard $\mathrm{N}$, Ansari R. Impact of Sumac on postprandial high-fat oxidative stress. PakJ Med Sci. 2013;29(1):340-5.

45. Rafieian-Kopaei M, Setorki M, Doudi M, Baradaran A, Nasri H. Atherosclerosis: process, indicators, risk factors and new hopes. Int J Prev Med. 2014;5(8):927-46.

46. Rafieian-Kopaei M. Medicinal plants for renal injury prevention. J Renal Inj Prev. 2013;2(2):63-5.

47. Nasri H, Rafieian-Kopaei M. Medicinal Plants And Antioxi- dants: Why They Are Not Always Beneficial? Iran J Public Health. 2014;43(2):255-7.

48. Nazar CMJ. Significance of diet in chronic kidney disease. Nephropharmacol. 2013;2(2):37-43.

49. Nasri H, Ahmadi A, Baradaran A, Nasri P, Hajian S, Pour-Arian A et al. A biochemical study on ameliorative effect of green tea $(\mathrm{Ca}-$ mellia sinensis) extract against contrast media induced acute kidney injury. J Renal Inj Prev. 2014;3(2):47-9.

50. Nasri H, Rafieian-Kopaei M. Medicinal Plants and New Concerns in Statin Consumption. Iran J Public Health. 2013;42(9):1071-2.

51. Baradaran A, Nasri H, Rafieian-Kopaei M. Comment on: Anti-Oxidative Stress Activity of Stachys lavandulifolia Aqueous Extract in Humans. Cell J. 2013;15(3):272-3.

52. Baradaran A, Madihi Y, Merrikhi A, Rafieian-Kopaei M, Nematbakhsh M, Asgari A. Nephrotoxicity of hydroalcoholic extract of Teucrium polium in Wistar rats. Pak J Med Sci. 2013;29(1):329-33.

53. Madihi Y, Merrikhi A, Baradaran A, Ghobadi S, Shahinfard N, Ansari R. Bioactive components and the effect of hydroalcoholic extract of Vaccinium myrtillus on postprandial atherosclerosis risk factors in rabbits. PakJ Med Sci . 2013;29(1):384-9.

54. Nasri H, Rafieian-Kopaei M. Effect of vitamin D on insulin resistance and nephropathy in type 2 diabetes. J Res Med Sci. 2014;19(6):581-2.

55. Nazar CMJ. Diabetic nephropathy; principles of diagnosis and treatment of diabetic kidney disease. J Nephropharmacol. 2014;3(1):15-20.

56. Nasri H, Baradaran A, Shirzad H, Rafieian-Kopaei M. New concepts in nutraceuticals as alternative for pharmaceuticals. Int $J$ Prev Med. 2014;5(12):1487-99.

57. Nasri H, Shirani S, Baradaran A. Lipids in association with leptin in maintenance hemodialysis patients. J Med Sci. 2006;6(2):173-9.

58. Serum cholesterol as a marker of nutrition in end-stage renal failure patients on renal replacement therapy. International $J$ Pharmacol. 2006;2(2):184-7.

59. Baradaran A, Nasri H, Rafieian-Kopaei M. Protection of renal tubular cells by antioxidants: current knowledge and new trends. Cell J. 2015;16(4):568-71.

60. Couser WG, Johnson RJ. Mechanisms of progressive renal disease in glomerulonephritis. Am J Kidney Dis. 1994;23(2):193-8.

61. Nasri H, Nematbakhsh M, Ghobadi S, Ansari R, Shahinfard N Rafieian-Kopaei M. Preventive and curative effects of ginger extract against histopathologic changes of gentamicin-induced tubular toxicity in rats. Int J Prev Med. 2013;4(3):316-21.

62. Baradaran A, Rafieian-Kopaei M. Histopathological study of the combination of metformin and garlic juice for the attenuation of gentamicin renal toxicity in rats. J Renal Inj Prev. 2013;2(1):15-21.

63. Baradaran A, Nasri H, Nematbakhsh M, Rafieian-Kopaei M. Antioxidant activity and preventive effect of aqueous leaf extract of Aloe Vera on gentamicin-induced nephrotoxicity in male Wistar rats. Clin Ter. 2014;165(1):7-11.

64. Nasri H, Nematbakhsh M, Rafieian-Kopaei M. Ethanolic extract of garlic for attenuation of gentamicin-induced nephrotoxicity in Wistar rats. Iran J Kidney Dis. 2013;7(5):376-82.

65. Rafieian-Kopaei M, Nasri H, Nematbakhsh M, Baradaran A, Gheissari A, Rouhi H, et al. Erythropoietin ameliorates genetamicin-induced renal toxicity: A biochemical and histopathological study. J Nephropathol. 2012;1(2):109-16.

66. Gaedeke J, Fels LM, Bokemeyer C, Mengs U, Stolte H, Lentzen $\mathrm{H}$. Cisplatin nephrotoxicity and protection by silibinin. Nephro Dial Transplant. 1996;11(1):55-62.

67. Nasri H, Rafieian-Kopaei M. Tubular Kidney Protection by Antioxidants. Iran J Public Health. 2013;42(10):1194-6.

68. Rafieian-Kopaei M, Baradaran A, Rafieian M. Plants antioxidants: From laboratory to clinic. J Nephropathol. 2013;2(2):152-3.

69. Hajian S. Renoprotective effects of green tea. J Nephropharmacol. 2013:2122.

70. Baliga R, Ueda N, Walker PD, Shah SV. Oxidant mechanisms in toxic acute renal failure. Drug Metab Rev.1999;31(4):971-97.

71. Nasri H, Ardalan MR, Rafieian-Kopaei M. Mechanistic Impacts of Medicinal Plants in Diabetic Kidney Disease. Iran J Public Health. 2014;43(9):1311-3.

72. Nasri H, Rafieian-Kopaei M. Protective effects of herbal antioxi- 


\section{Nasri Het al.}

dants on diabetic kidney disease. J Res Med Sci. 2014;19(1):82-3.

73. Baradaran A, Rabiei Z, Rafieian M, Shirzad H. A review study on medicinal plants affecting amnesia through cholinergic system. JHerbMed Pharmacol. 2012;1(1):3-9.

74. Baradaran A, Nasri H, Rafieian-Kopaei M. Oxidative stress and hypertension: Possibility of hypertension therapy with antioxidants.J Res Med Sci. 2014;19(4):358-67.

75. Nasri H, Baradaran A. Association of serum lipoprotein(a) with ultrasonographically determined early atherosclerotic changes in the carotid and femoral arteries in kidney transplanted patients. Transplant Proc. 2004;36(9):2683-6.
76. Baradaran A, Behradmanesh S, Nasri H. Association of body mass index and serum vitamin D level in healthy Iranian adolescents. Endokrynol Pol.2012;63(1):29-33.

77. MacLennan AH, Wilson DH, Taylor AW. The escalating cost and prevalence of alternative medicine. Prev Med.2002;35(2):166-73.

78. Kafeshani M. Ginger, micro-inflammation and kidney disease. $J$ Renal Endocrinol. 2015;1:e04.

79. Nasri H, Ahmadi A, Rafieian-Kopaei M, Bashardoust B, Nasri P, Mubarak M. Association of glomerular C4d deposition with various demographic data in IgA nephropathy patients; a preliminary study. J Nephropathol. 2015;4(1):19-23. 